\title{
Distribution of polyethylene glycol in suspensions of food particles, especially sugar-beet pulp and dried grass pellets
}

\author{
By J. W. CZERKAWSKI AND GRACE BRECKENRIDGE \\ Hannah Dairy Research Institute, Ayr
}

(Received 18 November 1968-Accepted 10 March 1969)

\begin{abstract}
I. It was shown that when polyethylene glycol (PEG) was added to suspensions of food particles in aqueous buffer solutions, its distribution in the total water of the food mass was not uniform. The rnarker was excluded from a large proportion of the water contained in the swollen food particles. This effect was independent of temperature, $\mathrm{pH}$, and, within limits, the time of contact.

2. It was shown that the theoretical concentration $\left(C_{0}\right)$, assuming a uniform distribution of marker, could be calculated from the observed concentration $(C)$, weight of food in suspension $(W)$ and the total volume of water $(V)$, using the equation $C=C_{0}(\mathrm{x}+b[W / V])$ where $b$ is constant for any given food. The addition of PEG solution to dry food particles gave a smaller effect.

3. The distribution of PEG was usually, but not invariably, more uniform in a suspension of roughages than in a suspension of concentrates.

4. Possible implications of these findings with respect to marker experiments with PEG are discussed.
\end{abstract}

The water-soluble marker, polyethylene glycol (PEG), has been extensively used since the technique for its application in rumen studies was developed by Hydén (I96I). It is possible, using this procedure, to estimate the volume of the liquid in the rumen and the rate of flow of liquid digesta in the gut of the ruminant. However, various contradictory results have been obtained and, in particular, the uniformity of distribution of PEG in suspensions of food particles has been questioned (Sperber, Hydén \& Ekman, 1953; Corbett, Greenhalgh \& Florence, r959; Manners \& Kidder, I968). Rarely have the results of estimations of volumes of the rumen fluid been checked by slaughter and direct measurements (e.g. Ulyatt, Blaxter \& McDonald, r967). The use of soluble markers in rumen studies was critically appraised by Warner \& Stacy (1968).

In some of our recent investigations, sugar-beet pulp was used as the sole constituent of the diet of sheep. When PEG was used as marker in these experiments, the calculated volumes of the rumen and the rates of flow of digesta were unreasonable (Czerkawski \& Paterson, 1968). Further experiments showed that the calculated volumes of water in the rumens of sheep receiving sugar-beet pulp were very low initially (4 1.), but increased considerably after $I_{5}$ weeks on this diet $\left(I_{3}-I_{5}\right.$ l.). The volume of rumen water in similar sheep receiving dried grass pellets was apparently normal at the start $(81$.$) , but decreased to about 61$. after 15 weeks. The ingestion of molassed sugar-beet pulp results in a considerable increase in the concentration of soluble sugar in the rumen and the increase in the calculated volume of rumen water could be explained by assuming that the animals became adapted to the diet of molassed sugar-beet pulp, and began to secrete increasing amounts of water into the 
rumen, thus washing out or diluting the added marker (Murray, Reid \& Sutherland, I 962 ; Engelhardt, I963). However, this would not explain the abnormally low calculated values of rumen water at the beginning of the experiments and it seemed that a non-uniform distribution of PEG in the suspension of food particles could be a contributing factor. The present work was undertaken to investigate this aspect of the problem.

\section{EXPERIMENTAL}

\section{Determination of $P E G$}

The concentrations of PEG (mol wt 4000; Koch-Light Laboratories Ltd, Colnbrook, Bucks) were determined by the method of Hydén (1955). In some instances, e.g. when water-extracted mainly fibrous food particles were used, the procedure was shortened by omitting the initial precipitation steps.

\section{Food particles}

Sugar-beet pulp and commercial dried grass pellets were used initially, but the distribution of PEG in suspensions of other food particles was also investigated. The samples were not ground, but the moisture content was determined. It was usually less than $3 \%$, and if necessary the samples were dried at $60^{\circ}$ until the moisture was reduced to below that figure.

In some experiments the system was simplified and water-soluble substances were removed by extraction. The samples ( $100 \mathrm{~g}$ ) were shaken intermittently for $\mathrm{I}-\mathbf{2} \mathrm{h}$ at $40^{\circ}$ with $\mathrm{I} \cdot 5 \mathrm{l}$. buffer solution (McDougall, $\mathrm{I} 948$ ). They were centrifuged at $700 \mathrm{~g}$ and the supernatant fluid was decanted. The extraction procedure was repeated three times, the residues were washed with water and freeze-dried until the moisture content was less than $3 \%$. When sugar-beet pulp and dried grass pellets were subjected to the extraction the yields of dry residues were $6 \mathrm{I}$ and $7^{2} \mathrm{~g}$ from sugar-beet pulp and dried grass respectively.

\section{Experimental procedures}

Samples of food particles $(0 \cdot 2-\mathrm{I} \cdot 0 \mathrm{~g})$ were weighed in centrifuge tubes and either buffer solutions or PEG solutions in water were added $\left(5^{-16} \mathrm{ml}\right)$. The samples were mixed and allowed to stand with intermittent stirring for $\mathrm{I} h$. Equal volumes of PEG solutions were then added to the tubes that already contained buffer solutions, and equal volumes of buffer solutions to those that contained PEG. In some tubes food particles were omitted or PEG solution was replaced by water to give suitable control values. The suspensions were stirred and again allowed to stand for $\mathrm{I} h$. The tubes were centrifuged at $700 \mathrm{~g}$ for $5^{-10} \mathrm{~min}$, and $\mathrm{I}-2 \mathrm{ml}$ of supernatant fluid were withdrawn for the determination of PEG.

The experiments were of two main types. In one type (A) the amounts of food and the volume of liquid added were kept constant and the concentrations of added PEG solutions were varied. In the second type $\left(B_{1}\right)$ constant concentrations of PEG in constant volumes of liquid were added to varying amounts of solid food particles. Finally, in a variant of the second type of experiment $\left(B_{2}\right)$, the volumes of liquid added were varied while the weight of food particles remained constant. 


\section{RESULTS}

\section{Exploratory work}

It became apparent at the start that when $V / 2 \mathrm{ml}$ of PEG solution containing $2 C_{0} \mathrm{mg} / \mathrm{ml}$ was added to dry sugar-beet pulp or dried grass suspended in $V / 2 \mathrm{ml}$ of buffer solution, the concentration of PEG in the supernatant fluid was not $C_{0}$. In fact, it was usually greater by $15-45 \%$. This effect decreased somewhat when the suspension was allowed to stand for longer than $24 \mathrm{~h}$, but did not change significantly up to $6 \mathrm{~h}$.

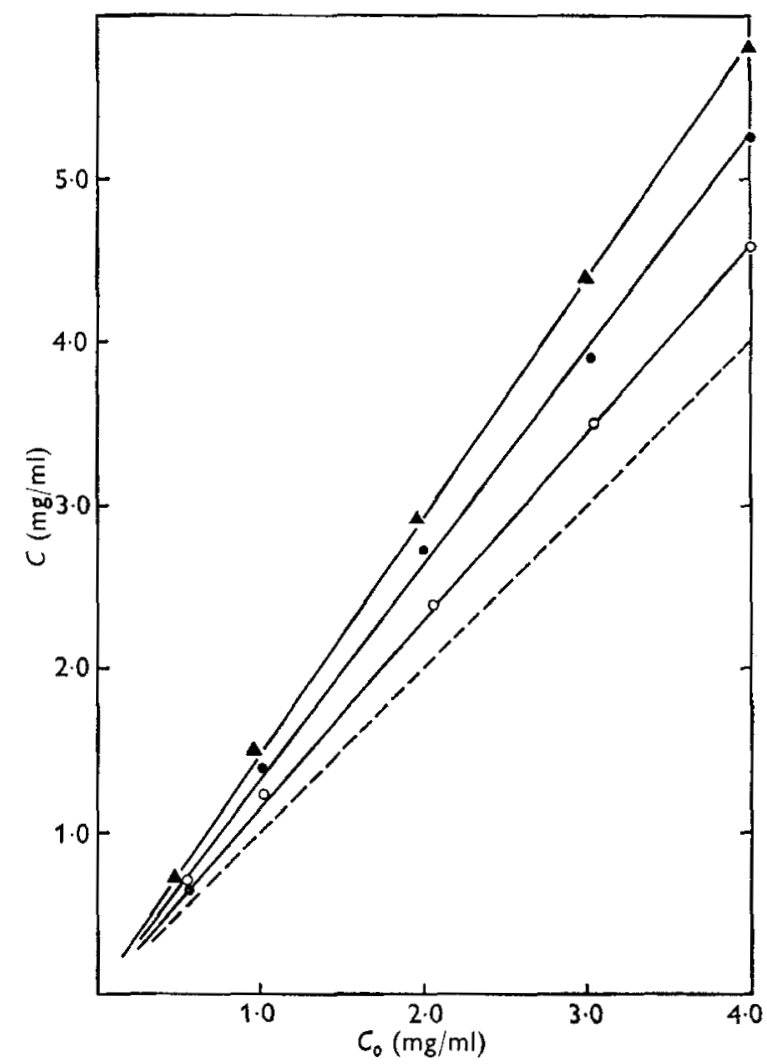

Fig. I. Variation in the observed concentration of PEG $(C)$ in the presence of extracted sugarbeet pulp (O), extracted dried grass $(O)$ and of unextracted sugar-beet pulp ( $\Delta$ ), with variation of the theoretical concentration of PEG $\left(C_{0}\right)$. The weight of extracted foods was $0.5 \mathrm{~g}$ and the weight of unextracted sugar-beet pulp was $\mathrm{I} \cdot 0 \mathrm{~g}$. The volume of liquid in each instance was ro ml. The broken line represents a relationship that would be obtained if the distribution of $P E G$ were uniform.

Diffusion is a slow process, and the observed small decrease in the above effect could be due to diffusion of PEG into the more accessible water spaces of the particles. When the suspensions of food particles were kept for periods of $\mathrm{I}-2 \mathrm{~h}$ at three different temperatures $\left(22^{\circ}, 40^{\circ}\right.$ and $\left.60^{\circ}\right)$ there was no significant change in the ratio of the concentrations of PEG to the theoretical concentration, the mean values and their 
standard deviations being $\mathrm{r} \cdot 34 \pm 0.0 \mathrm{r}$ and $\mathrm{r} \cdot 22 \pm 0.02$ for sugar-beet pulp and dried grass respectively. The effect was also independent of the $\mathrm{pH}$ of solutions between $\mathrm{pH} 2$ and $\mathrm{io}$. It seemed probable, therefore, that the main factor in excluding PEG from the water in food particles was a molecular sieve effect (Manners \& Kidder, 1968).

\section{Factors that affect the non-uniform distribution of PEG}

The results of one series of experiments, in which mainly extracted food samples of sugar-beet pulp and dried grass were used, are shown in Figs. I and 2. In these figures, and later on in the text, $C$ is the measured concentration of PEG, $C_{0}$ is the
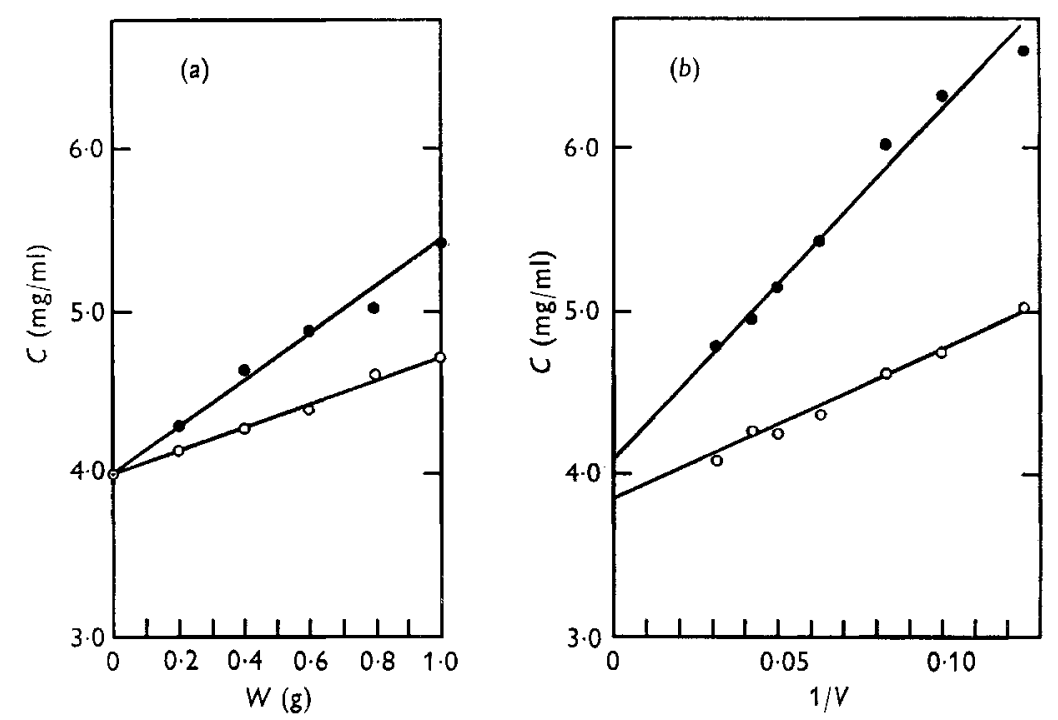

Fig. 2. (a) Variation of the concentration of PEG, with the weight of extracted sugar-beet pulp $(\circlearrowleft)$ and dried grass (O), when the concentration of PEG in the absence of food was $4.0 \mathrm{mg} / \mathrm{ml}$ and the volume of liquid was $20 \mathrm{ml}$. (b) Variation of the concentration of PEG, with the reciprocal of the final volume of liquid when equal volumes of PEG solutions containing $8.0 \mathrm{mg} / \mathrm{ml}$ were added to $0.5 \mathrm{~g}$ of extracted sugar-beet pulp (O) and to $0.5 \mathrm{~g}$ of dried grass $(0)$.

corresponding concentration of PEG if there were no food particles present, $W$ is the weight of extracted food used and $V$ is the total volume of the liquid. Clearly, with both foods, within the range of concentrations studied, $C$ was proportional to $C_{0}$ (Fig. I). It can be seen that $C$ was a linear function of $W$ (Fig $2 a$ ) and a linear function of $1 / V$ (Fig. $2 b$ ), Moreover, in each instance the intercepts were equal or nearly equal to $C_{0}$. In fact, the results can be accurately described by an empirical equation:

$$
C=C_{0}(\mathrm{I}+b[W / V]),
$$

where $b$ is a constant for any particular food and experimental conditions. The units of $b$ would depend on the units of $W$ and $V$, and in the present experiments are expressed in $\mathrm{ml} / \mathrm{g}$ dry extracted food. The values of $b$ obtained in this series of experiments with extracted foods varied from $6 \cdot 4-6 \cdot 8$ for sugar-beet pulp and from $3 \cdot I-3 \cdot 6$ for dried grass pellets. 
The results of one of the experiments with unextracted sugar-beet pulp are also given in Fig. I. The slope of the straight line was $1 \cdot 46$ units and since the volumes of liquids were constant at $10 \mathrm{ml}$, and the amount of sugar-beet pulp used in each instance was $\mathrm{I} \cdot \mathrm{O} \mathrm{g}$ (i.e. $0.6 \mathrm{I} \mathrm{g}$ of water-insoluble material), according to equation ( $\mathrm{I}$ ) the value of $b$ for that experiment was $7.6 \mathrm{ml} / \mathrm{g}$ dry extracted material. This is in reasonable agreement with the values of $b$ obtained with extracted sugar-beet pulp.

\section{Effect of variation of experimental conditions}

Since, in some of our experiments with animals, the PEG solution was added to dry food before it was given to the animals, in this series of experiments the procedure was varied accordingly. Volumes of PEG solution were added to dry food

Table $\mathrm{I}$. Values of the constant $\mathrm{b}$ in equation (1), obtained by varying the experimental procedure and the type of food particles

$\overbrace{\overbrace{(a)}^{\text {Sugar-beet pulp }}}^{\text {Value of } b(\mathrm{ml} / \mathrm{g})} \overbrace{(b)}^{\text {Dried grass pellets }}$

(a) Buffer solution added first and equal volumes of PEG solutions $I$ h later.

(b) PEG solutions added to dry food particles and buffer solutions added $\mathrm{I} h$ later.

* The values of $b$ calculated on the basis of the weight of dry extracted material.

particles (both extracted and unextracted) and, after $\mathrm{I} h$, equal volumes of buffer solutions were added. The values of $b$, given in Table $\mathrm{I}$, are means derived from the results of two series of such experiments. The results were quite analogous to those obtained previously but, in general, the effect was smaller.

For the unextracted samples, the values of $b$ were calculated from the weights of material that were insoluble in water. The values were in general not significantly different when extracted and unextracted foods were used, but the results were not as reproducible and began to deviate unpredictably from the above simple relation (equation I) when the concentration of the solid was greater than $0 \cdot \mathrm{I} \mathrm{g} / \mathrm{ml}$.

\section{Distribution of PEG in suspensions of various types of food}

Samples of foods commonly used in animal experiments were extracted with buffer solutions at $40^{\circ}$ as described in the experimental section. The results of the determinations of the constant $b$ are summarized in Table 2.

The values of $b(\mathrm{ml} / \mathrm{g}$ of dry extracted food) were large with sugar-beet pulp and decorticated groundnut, but not with the other concentrates tested. The values of $b$ for the fibrous rations did not vary greatly. However, it must be emphasized that the value for any particular sample of foodstuff will undoubtedly depend on such factors as the extent of grinding and, with roughages, on the stage of growth. An examination of the results in Table 2 shows that the values of $b$ increased with the increase in the 
content of buffer-soluble material in foods. A very rough estimate of the value of $b$ can be made by multiplying the concentration of water-soluble material ( $\mathrm{g} / \mathrm{g}$ food) by I8. Nevertheless, the procedure for determining $b$ is relatively simple, and it is best determined, using PEG, with the actual food under consideration.

Table 2. Percentage by weight of material extracted from various foods by buffer solutions and the values of the constant $\mathrm{b}$ in equation (1) obtained by adding PEG to suspensions of the extracted samples

\begin{tabular}{lcc}
\multicolumn{1}{c}{ Food } & $\begin{array}{c}\text { Material extracted } \\
(\%)\end{array}$ & $\begin{array}{c}\text { ml/g of dry } \\
\text { extracted food }\end{array}$ \\
Hay & 24 & $4 \cdot 2$ \\
Dried grass pellets & 28 & $3 \cdot 3$ \\
Dried grass & 29 & $4 \cdot 4$ \\
Oat meal & 18 & $3 \cdot 2$ \\
Barley meal & 24 & $4 \cdot 6$ \\
Cubes* & 29 & $4 \cdot 0$ \\
Decorticated groundnut & 34 & $6 \cdot 6$ \\
Sugar-beet pulp & 39 & $7 \cdot 1$ \\
These contained the following by weight: barley meal 24, oat meal 24, \\
\multicolumn{2}{c}{ dried grass meal 45, sugar-beet pulp 5 and salts 2. }
\end{tabular}

\section{DISCUSSION}

It is not known at present whether the uneven distribution of PEG demonstrated here applies to suspensions of partly digested food particles in the rumen. Assuming that this is so, it is possible using equation ( $\mathrm{I}$ ) to show the magnitude of error that might be incurred in assuming uniform distribution of PEG throughout the liquid phase.

Suppose a sheep is given a single meal of $\mathrm{I} \mathrm{kg}$ sugar-beet pulp and suppose a dose of PEG solution is given shortly after the meal. The dry weight of ingested insoluble food is $600 \mathrm{~g}$ and, furthermore, some insoluble food will be present in the rumen (say $200 \mathrm{~g}$ ). Thus, the total dry weight of insoluble material in the rumen is $800 \mathrm{~g}(W)$ and the volume of water in the rumen can be taken as $71 .(\mathrm{V})$. On substituting in equation (I) and using $b=7.6 \mathrm{ml} / \mathrm{g}$ extracted food (Table $\mathrm{s}$ ), we have:

$$
C=C_{0}(\mathrm{I}+b[W / V])=\mathbf{r} \cdot 87 C_{0} .
$$

Clearly, the observed concentration of PEG $(C)$ might be much greater than the concentration that would be obtained if the distribution of PEG in rumen water were uniform $\left(C_{0}\right)$. Since the calculation of the volume of rumen water from determinations of the concentrations of PEG in the rumen is based on the assumption that PEG is uniformly distributed (Hydén, I961), the implication is obvious. If, however, it can be shown that values for $b$ determined in vitro can be applied to values obtained in vivo it should be possible to use them to convert rumen water volumes obtained by this technique. 


\section{REFERENCES}

Corbett, J. L., Greenhalgh, J. F. D. \& Florence, E. (I959). Br. F. Nutr. 13, 337.

Czerkawski, J. W. \& Paterson, D. R. (1968). Proc. Nutr. Soc. 27, 33 A.

Engelhardt, W. (1963). Natürwissenschaften 50, 357 .

Hydén, S. (1 955). LantbrHögsk. Annlr 22, 139.

Hydén, S. (1961). LantbrHögsk. Annlr 27, 51.

Manners, M. J. \& Kidder, D. E. (г968). Br. F. Nutr. 22, 5 I 5.

McDougall, E. I. (1948). Biochem. F. 43, 99.

Murray, M. G., Reid, R. S. \& Sutherland, T. M. (1962). F. Physiol., Lond. 164, 26 P.

Sperber, I., Hydén, S. \& Ekman, J. (1953). LantbrHögsk. Annlr 20, 337.

Ulyatt, M. J., Blaxter, K. L. \& McDonald, I. (1967). Anim. Prod. 9, 463.

Warner, A. C. I. \& Stacy, B. D. (I 968). Br. F. Nutr. 22, 369. 